\title{
Renal artery entrapment - anatomical risk factors rating
}

\author{
A. Arazińska1 , M. Polguj², M. Topol ${ }^{3}$, A. Wojciechowski ${ }^{1}$, Ł. Trębiński ${ }^{1}$, L. Stefańczyk ${ }^{1}$ \\ ${ }^{1}$ Department of Radiology, Medical University of Lodz, Poland \\ 2Department of Angiology, Interfaculty Chair of Anatomy and Histology, Medical University of Lodz, Poland \\ ${ }^{3}$ Department of Normal and Clinical Anatomy, Interfaculty Chair of Anatomy and Histology, \\ Medical University of Lodz, Poland
}

[Received: 22 October 2015; Accepted: 16 February 2016]

Background: Cases of renal artery entrapment (RAE) by extrinsic compression have been infrequently reported in the literature. We aimed to describe RAE and elucidate anatomical factors that may be related to renal artery stenosis.

Materials and methods: Two hundred and four patients' computed tomography scans made for various reasons in Radiology Department from 2011 to 2015 were retrospectively analysed and 7 cases of RAE were found. Authors studied the level of origin of renal arteries vs. coeliac trunk (CT), superior mesenteric artery (SMA) and vertebrae. Diameter of renal arteries, distance between main left renal artery (LRA) and right renal artery (RRA) as well as renal arterial patterns were also investigated. Results: The origin of main renal arteries off the aorta was between the upper margin of $L 1$ and lower margin of $L 2$ vertebra, with the predominant lower 1/3 of $L 1$ vertebra and $L 1$ intervertebral disc. However, in patients with highest range of stenosis of renal artery the origin was most commonly located at the level of Th12 intervertebral disc and upper part of L1. Statistically significant relationships were proven between range of stenosis and level of origin of stenotic renal artery vs. vertebrae (Pearson's correlation coefficient: $-0.393, p<0.01$ ), distance between main LRA and RRA (Pearson's correlation coefficient: 0.398, $p<0.0001$ ), renal artery-CT distance (Pearson's correlation coefficient: $-0.263, p<0.0001$ ), renal artery-SMA distance (Pearson's correlation coefficient: $-0.149, p<0.033$ ).

Conclusions: Analysis of RAE allowed finding anatomical factors of renal artery stenosis and classifying them regarding to their importance. Relationship of renal artery origin vs. vertebrae and distance between main LRA and RRA were proven the most important. However, distances between higher originated renal artery and CT, higher originated renal artery and SMA should also be taken into consideration. (Folia Morphol 2016; 75, 4: 486-492)

Key words: renal artery entrapment, renal artery compression, median arcuate ligament syndrome, hypertension, computed tomography angiography

\section{INTRODUCTION}

Renal artery stenosis (RAS) is associated with compromised renal perfusion, hypertension, ischaemic ne- phropathy, and end-stage renal failure. The majority of cases are due to atherosclerotic renal artery (RA) disease and fibromuscular dysplasia (FMD) in about $10 \%$ of cases

Address for correspondence: Assoc. Prof. M. Polguj, MD, PhD, Department of Angiology, Medical University of Lodz, ul. Narutowicza 60, 90-136 Łódź, Poland, tel: +48 6304949, e-mail: michal.polguj@umed.lodz.pl 
Table 1. Mean values of measured distances between investigated vessels and mean levels of origin of investigated vessels in respect to vertebrae

\begin{tabular}{|c|c|c|c|c|c|c|c|c|c|}
\hline \multicolumn{6}{|c|}{ Mean values of distances between investigated vessels [mm] and SD } & \multirow{3}{*}{$\begin{array}{l}\text { Mean level of } \\
\text { origin of RRA }\end{array}$} & \multirow{3}{*}{$\begin{array}{l}\text { Mean level of } \\
\text { origin of LRA }\end{array}$} & \multirow{3}{*}{$\begin{array}{c}\text { Mean level of } \\
\text { origin of CT }\end{array}$} & \multirow{3}{*}{$\begin{array}{l}\text { Mean level of } \\
\text { origin of SMA }\end{array}$} \\
\hline \multicolumn{2}{|c|}{ Main LRA-RRA } & \multicolumn{2}{|c|}{ RA-CT } & \multicolumn{2}{|c|}{ RA-SMA } & & & & \\
\hline Distance & SD & Distance & SD & Distance & SD & & & & \\
\hline 5.97 & 6.57 & 25.53 & 6.59 & 11.77 & 5.56 & Lower $1 / 3 \mathrm{~L} 1$ & L1 ID & Th12 ID & Middle $1 / 3 \mathrm{~L} 1$ \\
\hline
\end{tabular}

CT — coeliac trunk; ID — intervertebral disk; LRA — left renal artery; RA — renal artery; RRA — right renal artery; SD — standard deviation; SMA — superior mesenteric artery

and other less common pathologies [12]. Lumen of renal artery may be reduced due to entrapment. Congenital abnormalities such as abnormal musculotendinous fibres, high ectopic renal artery origin or hypertrophic diaphragmatic crus were found to be responsible for these entrapments. It was first described by D'Abreu who reported in 1962 two cases that were proven by surgery [5].

Since this first description, reports of renal artery entrapment (RAE) by the diaphragm have been reported infrequently in the literature and high RA origin is commonly known as a predictor of $\operatorname{RAE}[3,10,17,19$, 20]. Entrapment syndromes also include entrapment of coeliac trunk (median arcuate ligament syndrome), superior mesenteric artery, aorta, renal vein. Symptomatic patients are usually young with impaired quality of life. Successful treatment can produce great benefit, making knowledge of these conditions essential [13, 15]. In this study, we did not concentrate on clinical background. We report on a series of RAE cases and attempt to focus on assessing anatomical factors that may have impact on vascular disorder.

\section{MATERIALS AND METHODS}

Abdominal computed tomography scans with intravenous contrast were performed with subsequent sagittal, coronal, and three-dimensional reformations. The patients underwent contrast-enhanced abdominal computed tomography or computed tomography angiography (CT-64-row MDCT scanner, Light-Speed VCT, GE, Waukesha, Wisconsin, US; slice thickness $0,625 \mathrm{~mm}$ ) for various reasons in Radiology Department. Two hundred and four consecutive patients (85 women, 119 men, mean age 39.67 ) aged up to 60 years were examined. The limit of age up to 60 years was established in order to exclude cases of narrowing of renal arteries due to atherosclerosis. Additionally, during analysis of patients' examinations, they were verified for atherosclerotic changes' presence. Cases with atherosclerotic changes were rejected. We also analysed 7 cases of patients who have RAS resulting from anatomical conflicts ( 6 women, 1 man, mean age 43.87). In order to evaluate anatomical risk factors of $R A E$, the level of origin of renal arteries, coeliac trunk (CT), superior mesenteric artery (SMA) in respect to vertebrae were studied. The diameter of renal arteries and renal arterial patterns were investigated and following distances were measured: main left renal artery-right renal artery (LRA-RRA), CT-higher originated RA, SMA-higher originated RA. We aimed to define high RA origin not only in respect to the vertebrae, but also to attempt to discover the relevance of its origin in respect to CT and SMA origin. Statistical analysis was performed with SPSS software. Collection and analysis of data was conducted with approval from local ethical committee (approval number: RNN/259/15/KE).

\section{RESULTS}

The origin of main renal arteries off the aorta was between the upper margin of $L 1$ and lower margin of $L 2$ vertebra, with the predominant lower $1 / 3$ of $L 1$ vertebra and L1 intervertebral disc. A single RA was present in both kidneys in $65 \%$ of the patients. More than one RA was found in $35 \%$ of the patients. More than one RA was observed on the right side in $22 \%$ of the patients and on the left side in $28 \%$ of the patients. In $13 \%$ of the patients, there was more than one RA on both sides.

Predominately, level of origin of CT and SMA were Th12 intervertebral disc and middle $1 / 3$ of $L 1$, respectively. Mean values of measured distances between investigated vessels are summed up in the table (Table 1).

In the study dominated cases with range of RA narrowing up to $10 \%, 1$ case with narrowing of the vessel $17 \%$. These most common findings resulted from flexure in course of the vessel. There were no visible marked extrinsic compressions producing haemodynamically significant stenoses. There were also 7 outstanding RAE with value of stenosis grater or equal than $25 \%$ that were diagnosed in 7 patients. The defined stenoses of renal arteries were observed in 3 cases on the left side, in 4 cases of the right side 


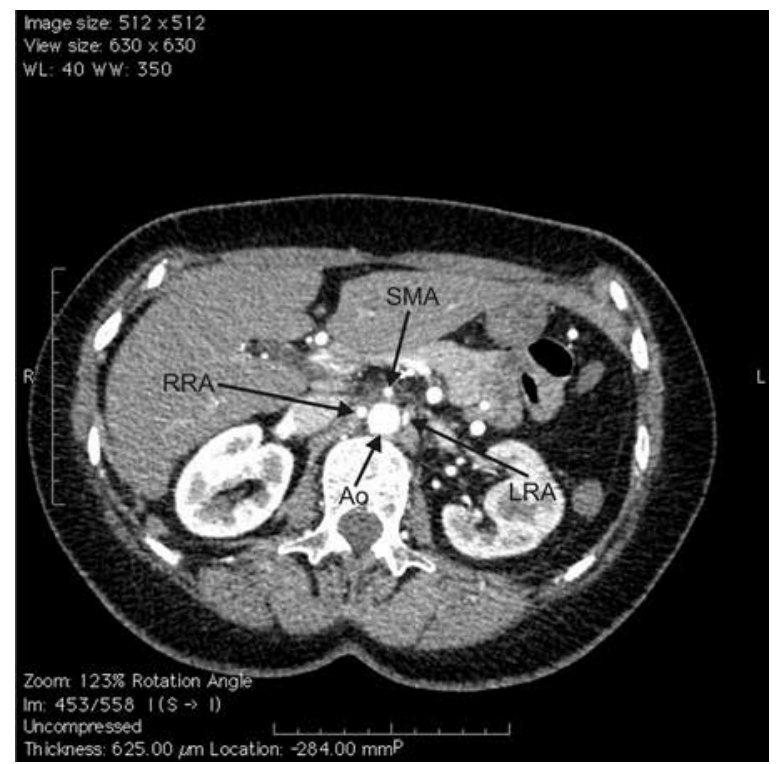

Figure 1. Abdominal computed tomography angiography, transverse scan; Ao — abdominal aorta; LRA — left renal artery (narrowed); RRA — right renal artery; SMA — superior mesenteric artery.

(Fig. 1). Level of origin of narrowed vessels ranged from upper 1/3 of Th12 vertebra to upper 1/3 of L2 vertebra, but most commonly it was located ( 2 cases) at the level of Th12 intervertebral disc and upper part of L1. Values of stenosis ranged from $25 \%$ to $60 \%$ (with the lumen of stenotic artery at the point of narrowing: $1.7-4.3 \mathrm{~mm}$ ). The highest values of stenosis were noticed in cases with high level of origin of stenotic arteries (at the level of Th12 intervertebral disc - upper $1 / 3$ of L1 vertebra). Significantly, in 6 of the reported cases, narrowed vessel was located as the highest of all this patient's renal arteries

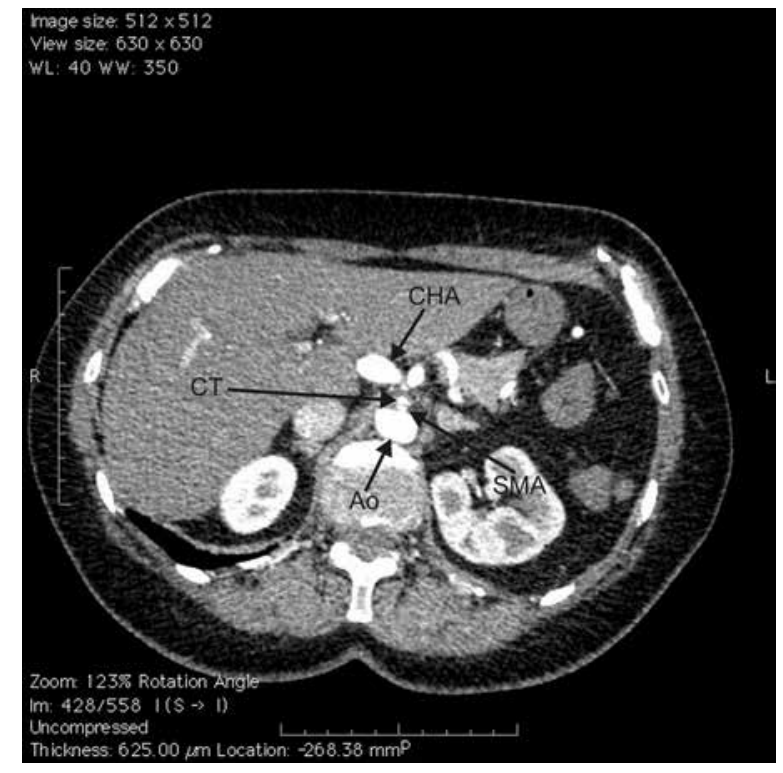

Figure 3. Abdominal computed tomography angiography, transverse scan; Ao — abdominal aorta (modelled); $\mathrm{CHA}$ — common hepatic artery (spindle shape widened); CT — coeliac trunk (narrowed); SMA — superior mesenteric artery (narrowed).

(regardless whether patient had single or multiple renal arteries on this side). In 6 of presented cases stenoses resulted from ostial compression of renal arteries by diaphragmatic crus (Fig. 2), in 1 patient single ectopic thoracic RA originating in the thorax was depicted. In 1 case with $46 \%$ RAS accompanied by CT and SMA stenosis, narrowed artery originated off aorta $2 \mathrm{~mm}$ lower than RA on the opposite side (Fig. 1). In 4 cases narrowing of RA lumen was accompanied by other abdominal vessels abnormalities - CT stenosis due to median arcuate ligament (Figs. 3, 4), SMA stenosis (Fig. 3) or aortic kinking on account of diaphragmatic
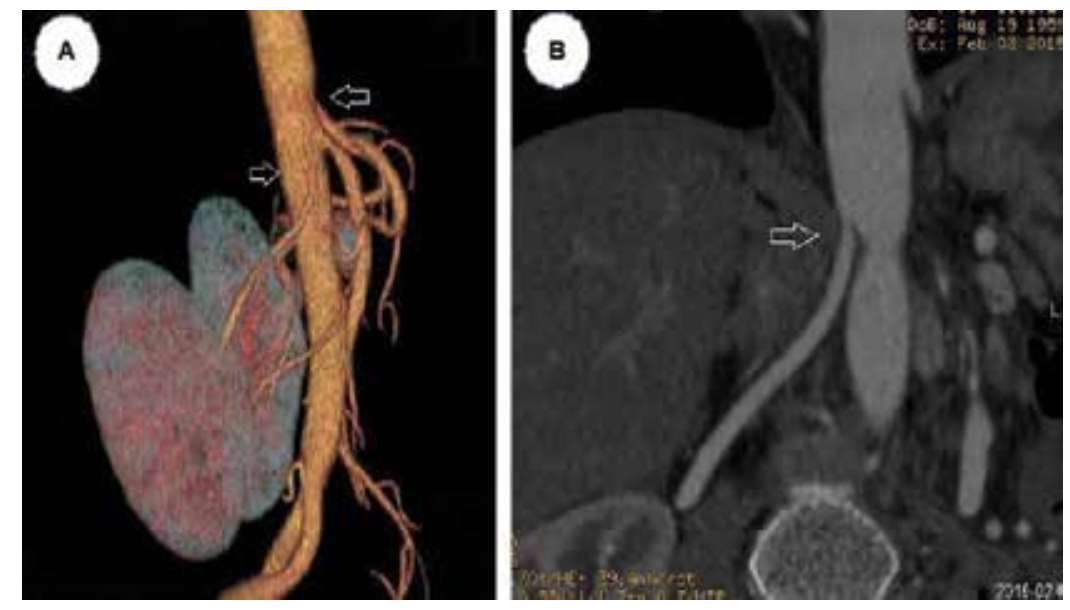

Figure 2. Abdominal computed tomography angiography; A. Volume Rendering right arrow — entrapped right renal artery, left arrow — coeliac trunk (narrowed); B. Coronal scan, arrow — ostial entrapment of right renal artery by diaphragmatic crus. 


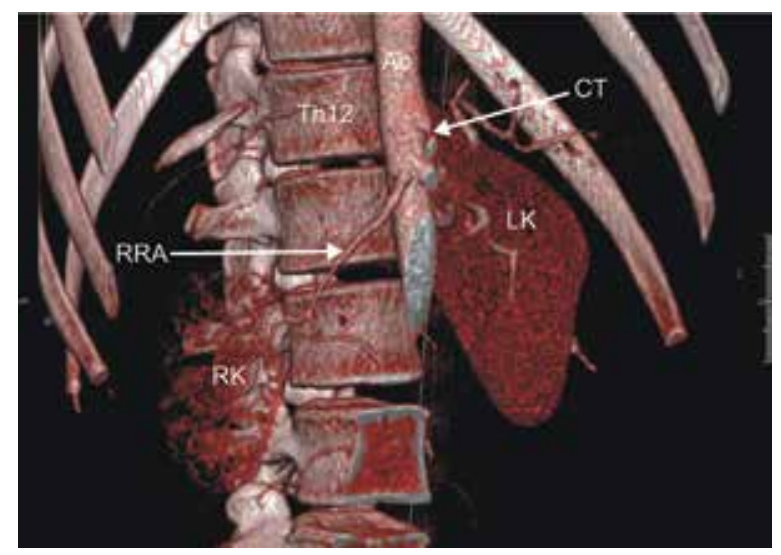

Figure 4. Abdominal computed tomography angiography, Volume Rendering; Ao — abdominal aorta; CT — coeliac trunk (narrowed); LK — left kidney; RK — right kidney; RRA — right renal artery (modelled); Th12 - twelfth thoracic vertebra.

crus. In one of the presented cases RA and CT were modelled due to compression of diaphragmatic crus, and followed by reduced dimensions of the right kidney. Although the narrowing of RA lumen owing to modelling might appear to be insignificant, but impaired renal function on this side was confirmed by angiography (Fig. 4). In 2 cases common origin of CT and SMA was observed. Among patients with the highest values of stenosis we noted various renal arterial patterns. The predominant was 1 RA per kidney
(4 women). In remaining cases, in 2 patients (1 woman, 1 man), RAS was revealed on the side where multiple renal arteries were observed. In 1 case multiple renal arteries were observed on the opposite side. In all of the depicted cases stenosis regarded to main RA. Data of reported cases are summed up in the Table 2.

Analyses between range of stenosis and level of origin of stenotic RA in respect to vertebrae (Pearson's correlation coefficient: $-0.393, p<0.01$ ), main LRA-RRA distance (Pearson's correlation coefficient: 0.398, $\mathrm{p}<0.0001$ ), RA-CT distance (Pearson's correlation coefficient: $-0.263, p<0.0001$ ), and RA-SMA distance (Pearson's correlation coefficient: $-0.149, p<$ $<0.033)$ presented statistically significant relationship. Remarkably, our analysis revealed that the most important anatomical risk factors of stenosis are level of origin of narrowed artery in respect to vertebrae (Fig. 5) and distance between main LRA and RRA. Lower importance in the rating have RA-CT (Fig. 6A) and RA-SMA (Fig. 6B) distances. Statistically significant relationship was not shown between RAS and level of origin of CT or SMA.

\section{DISCUSSION}

Since the first report by D'Abreu, several cases of RAE have been reported in the literature $[3,10,17,19,20]$. Similarly as observed in the presented cases, RAE usually develops in a RA with its origin high on the aorta.

Table 2. Summary of data of cases with the range of stenosis $\geq 25 \%$

\begin{tabular}{|c|c|c|c|c|c|c|c|c|}
\hline Patient & $\begin{array}{c}\text { Age } \\
\text { [years] }\end{array}$ & Sex & $\begin{array}{l}\text { Renal arterial } \\
\text { pattern }\end{array}$ & $\begin{array}{c}\text { Com- } \\
\text { pressed } \\
\text { vessel }\end{array}$ & $\begin{array}{c}\text { Stenosis } \\
{[\%]}\end{array}$ & $\begin{array}{l}\text { Level of origin } \\
\text { of stenotic RA } \\
\text { vs. vertebrae }\end{array}$ & $\begin{array}{c}\text { Other abdominal } \\
\text { vessels } \\
\text { abnormalities }\end{array}$ & $\begin{array}{c}\text { Mechanism } \\
\text { of compression }\end{array}$ \\
\hline 1 & 46 & $\mathrm{~F}$ & $\begin{array}{l}\text { R:A } \\
\text { L:2A }\end{array}$ & RRA & $30 \%$ & Th 12 ID & $\begin{array}{l}\text { Common origin of } \\
\text { CT and SMA }\end{array}$ & $\mathrm{DC}$ \\
\hline 2 & 28 & M & $\begin{array}{l}R: 2 A \\
L: 2 A^{a}\end{array}$ & LRA & $25 \%$ & Upper 1/3 L2 & - & $D C$ \\
\hline 3 & 57 & $F$ & $\begin{array}{l}\text { R:A } \\
\text { L:A }\end{array}$ & LRA & $46 \%$ & Upper 1/3 L1 & CT, SMA stenosis & $\mathrm{DC}$ \\
\hline 4 & 30 & $F$ & $\begin{array}{l}R: A \\
L: A\end{array}$ & LRA & $60 \%$ & Upper 1/3 Th12 & $\begin{array}{l}\text { Aortic kinking, common } \\
\text { origin of CT and SMA }\end{array}$ & $\begin{array}{l}\text { Single ectopic thoracic } \\
\text { renal artery originating } \\
\text { in the thorax }\end{array}$ \\
\hline 5 & 56 & $F$ & $\begin{array}{l}\mathrm{R}: 2 \mathrm{~A} \\
\mathrm{~L}: 2 \mathrm{~A}\end{array}$ & RRA & $37 \%$ & Middle 1/3 L1 & CT stenosis & $\mathrm{DC}$ \\
\hline 6 & 30 & $\mathrm{~F}$ & $\begin{array}{l}\text { R:A } \\
\text { L:A }\end{array}$ & RRA & $30 \%$ & Th12 ID & CT stenosis & $D C$ \\
\hline 7 & 60 & $\mathrm{~F}$ & $\begin{array}{l}\text { R:A } \\
\text { L:A }\end{array}$ & RRA & $35 \%$ & Lower 1/3 L1 & - & $D C$ \\
\hline
\end{tabular}

aEarly division of renal artery $(<10 \mathrm{~mm}$ from origin); $\mathrm{A}$ - single renal artery; $2 \mathrm{~A}$ - two renal arteries; $C T$ - coeliac trunk; DC — ostial compression of RA by diaphragmatic crus; $\mathrm{F}$ - female; ID - intervertebral disk; $\mathrm{L}$ - renal arterial pattern on the left side; $L R A$ - left renal artery; $M$ - male; $R$ — renal arterial pattern on the right side; $R A$ - renal artery; RRA — right renal artery; SMA — superior mesenteric artery 


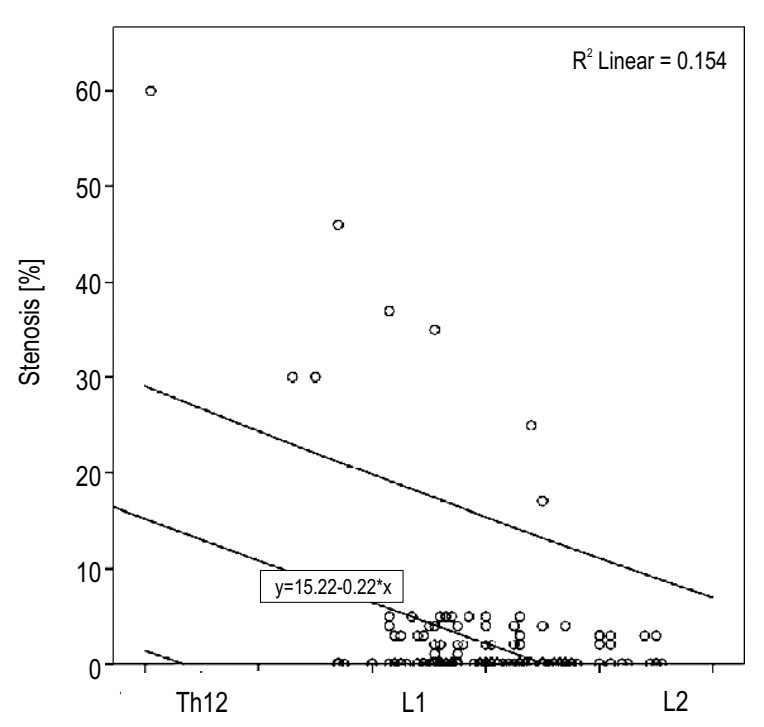

Figure 5. Relationship between range of renal artery stenosis and level of origin of narrowed artery (axis $\mathrm{X}$ - beginning-upper margin of Th12, end - lower margin of L2 intervertebral disk; due to origin of renal arteries in studied patients occurred between upper margin of Th12 - highest level and lower margin of L2 — lowest level).

In our study we managed to assess distances between selected abdominal vessels due to discovering possible relationships. Analyses between range of RAS and level of its origin in respect to vertebrae, main LRA-RRA distance, RA-CT distance, RA-SMA distance showed statistically significant relationships. The strongest relationship was shown between range of RAS and level of its origin in respect to vertebrae (Pearson's correlation coefficient: $-0,393, p<0.01$ ) (Fig. 5) and range of RAS and distance between main LRA and RRA (Pearson's correlation coefficient: 0.398 , $p<0.0001$ ). We managed to confirm that high RA origin is a risk factor of entrapment of the artery. It is particularly significant when high RA origin coexists with narrow hiatus of diaphragm. In our study high RA origin revealed to be important risk factor of RAS.

Reports in the literature revealed that congenital abnormalities such as abnormal musculotendinous fibres, high ectopic RA origin, hypertrophic diaphragmatic crura or psoas muscle band anomaly were responsible for these entrapments. Renal artery entrapments seem rather related to an abnormal relationship between the RA and the diaphragmatic crus, the origin of the artery being covered by the diaphragmatic crus. However, occurrence of RAE in elderly patients [19] suggests that these compressions may not be congenital but in favour of changes in relationships between the aorta and musculoskeletal structures over time. In
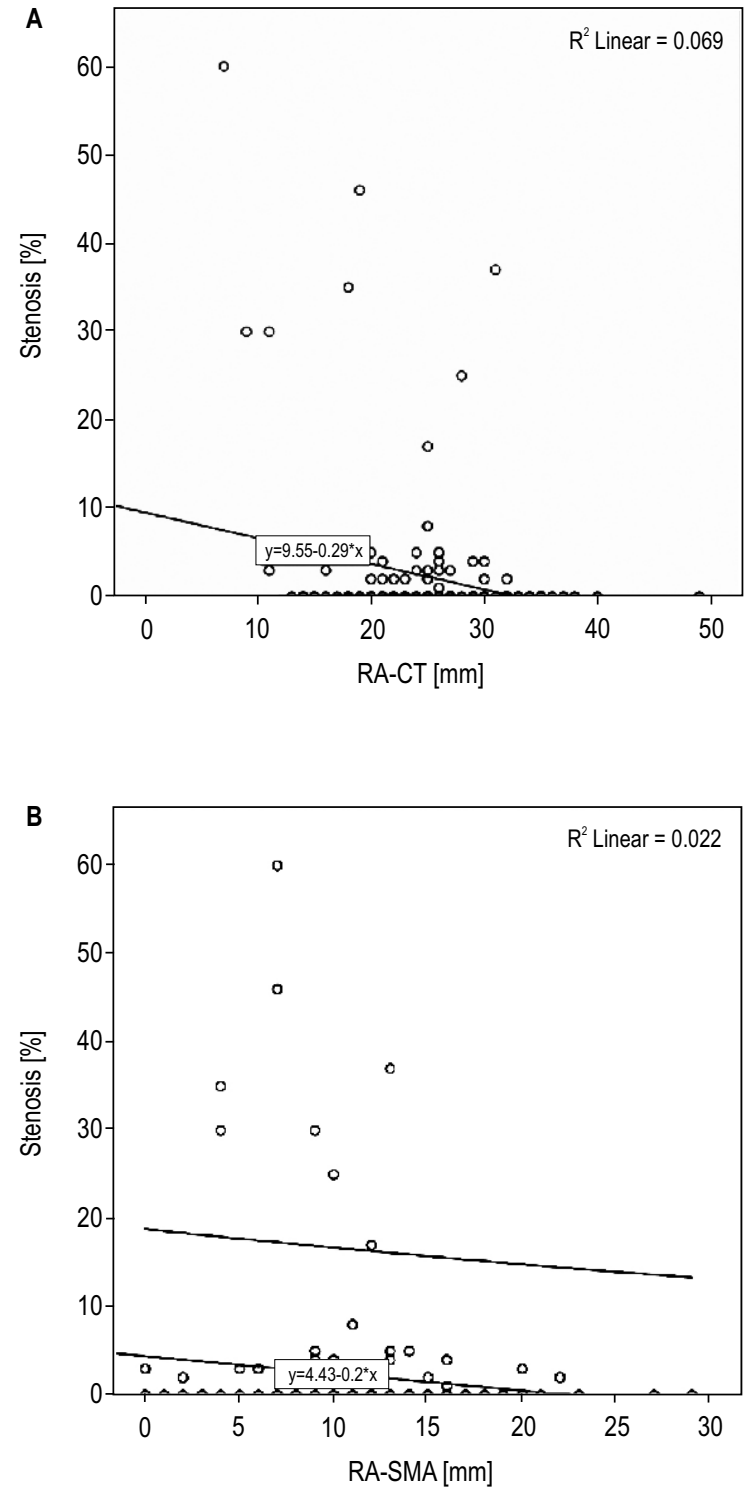

Figure 6. Relationship between range of RA stenosis and RA-CT distance $(\mathbf{A})$ and relationship between range of RA stenosis and RA-SMA distance (B); CT — coeliac trunk; RA — renal artery; SMA - superior mesenteric artery.

our study, renal arteries compressions were noticed mainly in younger patients (mean age: 43).

The best way to detect arterial compressions is systematically analysing relationships between renal arteries and the diaphragm when looking for RAS. Thony et al. [19] demonstrated two angiographic features suggesting RAE: renal arteries descending down and close to the aorta, and a concentric ostial stenosis in a patient free of atheroma.

Literature review suggests that RAE is more common on the left side. The mechanism evoked is an 
anomaly of migration of the kidneys [3, 18], which seems to be more common on the left side. The diaphragmatic fibres cause verticalisation of the root of the RA and lead to stenosis $[4,8,19]$.

During kidney migration to the retroperitoneal abdomen from the pelvis, metanephros vasculature is dynamic. Ultimately, the lowest suprarenal artery develops into the main single RA from the middle group, while more caudal and cephalic vessels degenerate. Thus, failure of kidney migration and persistence of middle group vasculature are common reasons for anomalous (abnormal course and/or origin of main vessel) renal arteries. The persistence of cranial group lateral mesonephric arteries was the likely cause for the rare main thoracic RA origin reported [7].

In one of our cases left kidney was located in a normal lumbar position with a single ectopic thoracic $\mathrm{RA}$ originating in the thorax, above the diaphragmatic dome, at the level of the upper $1 / 3$ of the Th12 vertebral body. Thoracic aorta was kinked and its compression by the median arcuate ligament was revealed. Due to thoracic aorta kinking, origins of CT and LRA were $10 \mathrm{~mm}$ away from each other, but perpendicularly the distance came to $3 \mathrm{~mm}$. The distance between origins of LRA and RRA equalled $62 \mathrm{~mm}$ [2]. With regard to literature review, the most common configuration originates from the lower margin of the L1 vertebra (25\%) on the right side and from the upper margin of the L2 vertebra (24\%) on the left side [14]. However, reports have noted, among others, cephalic variants originating as high as the T11 vertebral body [7]. The ectopic origin of a single RA with a normal kidney position is rare. A comprehensive literature demonstrated only 12 reports of this rare anatomic variant. There are also several reports of multiple ectopic renal arteries in the literature [11].

Occasionally, in addition to the RA, the constricting effects may also be exerted on the SMA and the CT $[8,10]$. We reported 3 cases presenting this disorder (Fig. 3). Computed tomography angiograms demonstrated a characteristic focal narrowing in the proximal coeliac axis. The focal narrowing had a characteristic hooked appearance, which helped distinguish this condition from other causes of coeliac artery narrowing, such as atherosclerotic disease [9]. Coexistence of extrinsic compression by crura of diaphragm on CT and RA is very infrequent and only a few cases have been reported in the literature [8]. Therefore three presented cases seem to be exceptional.
Our analysis showed that distance between main LRA and RRA is significant factor of RAS. It may be difficult to use this factor, especially in cases with multiple renal arteries in their renal arterial pattern. Sometimes in these patients, finding main RA among a few with similar diameter and course may be impossible. Additionally, superior polar artery is more likely to be compressed than hilar one.

Features like RA-CT and RA-SMA distances respectively seem to be less significant risk factors of RAS. However, the analysis suggests that these features, not only RA origin in respect to vertebrae and distance between main LRA and RRA, should be taken into consideration during evaluation of examination as possibly important factors of RAS.

The relationship between the SMA and the renal ostia is also an important factor when considering diagnostic renal arteriography and endovascular interventions, such as balloon angioplasty and endoluminal stenting [11].

Among our cases with the highest values of stenosis we noted different renal arterial patterns. The predominant was 1 RA per kidney (4 women). In remaining cases in 2 patients ( 1 woman, 1 man) RAS was revealed on the side where multiple renal arteries were observed. In 1 case multiple arteries were observed on the opposite side. In the literature a few cases of stenotic accessory renal arteries are also presented. A case of bilateral RAE by diaphragmatic crus was also noted $[6,16]$.

Data for our study were collected due to patients' computed tomography scans analysis. Computed tomography scan examination may overestimate these stenoses because the artery is often deformed (oval shape of the arterial lumen) without significant narrowing of the lumen. Moreover, some of these compressions disappear during expiration while $\mathrm{CT}$ is performed during inspiration. Conversely, angiography may underestimate these stenoses because it may be difficult to bring the initial segment of the renal artery out of the aorta as the artery is compressed against it. Therefore, it may be sometimes difficult to assess the role of the RAE in generating systemic hypertension. In these cases, Duplex ultrasound and intra-arterial blood pressure measurements may be useful. Venous sampling should also be of interest [19].

Compression of RA by the crus of the diaphragm should be investigated in proximal RAS in young hypertensive patients without other cardiovascular risk factors and in patients in whom fibromuscular 
dysplasia is unlikely. Once the renal entrapment syndrome is confirmed, surgical management should be considered. New treatment methods are being evaluated including botulinum injection, which may provide an alternative to surgical management especially before the intervention [18].

Knowledge of the abnormalities of renal arteries is crucial in patients with hypertension. It has grown in importance with increasing number of renal transplants, vascular reconstructions and various surgical and radiological techniques performed in recent years [1].

\section{CONCLUSIONS}

We managed to evaluate anatomical risk factors of RAS. Our investigation suggests that high origin is not the only risk factor of this disorder. Main LRA-RRA, $\mathrm{RA}-\mathrm{CT}$, and RA-SMA distances should be also taken into account as possibly considerable risk factors.

\section{REFERENCES}

1. Ali Mohammed AM, Elseed Abdalrasol RG, Alamin Abdalhai K, Gommaa Hamad M (2012) Accessory renal vessels. Acta Inform Med, 20: 196-197. doi: 10.5455/ aim.2012.20.196-197.

2. Arazińska A, Polguj M, Wojciechowski A, Trębiński $Ł$, Stefańczyk L (2015) An unusual case of left renal artery compression: a rare type of median arcuate ligament syndrome. Surg Radiol Anat, 2016; 38: 379-382. doi: 10.1007/s00276-015-1478-8.

3. Baguet JP, Thony F, Sessa C, Mallion JM (2003) Stenting of a renal artery compressed by the diaphragm. J Hum Hypertens, 17: 213-214.

4. Clément C, Ruiz R, Costa-Foru B, Nicaise H (1990) Extrinsic compression of the renal artery by diaphragmatic crus. Ann Vasc Surg, 4: 305-308

5. D'abreu, Stricland B (1962) Developmental renal-artery stenosis. Lancet, 2: 517-521.

6. Déglise S, Corpataux JM, Haller C, Binaghi S, Meuwly JY, Qanadli SD (2007) Bilateral renal artery entrapment by diaphragmatic crura: a rare cause of renovascular hypertension with a specific management. J Comput Assist Tomogr, 31: 481-484.

7. Delasotta LA, Olivieri B, MalikA, Nguyen C, Bhatia V, Burke W (2015) Thoracic renal artery: a rare variant. A case study and literature review. Surg Radiol Anat, 37: 561-564. doi: 10.1007/s00276-014-1379-2.

8. Gaebel G, Hinterseher I, Saeger HD, Bergert H (2009) Compression of the left renal artery and celiac trunk by diaphragmatic crura. J Vasc Surg, 50: 910-914. doi: 10.1016/j.jvs.2009.05.004.

9. Horton KM, Talamini MA, Fishman EK (2005) Median arcuate ligament syndrome: evaluation with $\mathrm{CT}$ angiography. Radiographics, 25: 1177-1182.

10. Kopecky KK, Stine SB, Dalsing MC, Gottlieb K (1997) Median arcuate ligament syndrome with multivessel involvement: diagnosis with spiral CT angiography. Abdom Imaging, 22: 318-320.

11. Matusz P, Miclăuş GD, Gabriel A, Catereniuc I, Olariu S, Tubbs RS, Loukas M (2015) Single ectopic thoracic renal artery associated with a normal kidney position and renal artery stenosis : a case report and review of literature. Rom J Morphol Embryol, 56: 557-562.

12. Mohan IV, Bourke V (2015) The management of renal artery stenosis: an alternative interpretation of ASTRAL and CORAL. Eur J Vasc Endovasc Surg, 49: 465-473. doi: 10.1016/j.ejvs.2014.12.026.

13. Noorani A, Walsh SR, Cooper DG, Varty K (2009) Entrapment syndromes. Eur J Vasc Endovasc Surg, 37: 213-220. doi: 10.1016/j.ejvs.2008.10.019.

14. Özkan U, Oğuzkurt L, Tercan F, Kizilkiliç O, Koç Z, Koca N (2006) Renal artery origins and variations: Angiographic evaluation of 855 consecutive patients. Diagn Interv Radiol, 12: 183-186.

15. Polguj M, Topol M, Majos A (2013) An unusual case of left venous renal entrapment syndrome: a new type of nutcracker phenomenon? Surg Radiol Anat, 35: 263-267. doi: 10.1007/s00276-012-1027-7.

16. Rountas C, Vlychou M, Vassiou K, Liakopoulos V, Kapsalaki E, Koukoulis G, Fezoulidis IV, Stefanidis I (2007) Imaging modalities for renal artery stenosis in suspected renovascular hypertension: prospective intraindividual comparison of color Doppler US, CT angiography, GD-enhanced MR angiography, and digital substraction angiography. Ren Fail, 29: 295-302.

17. Sari S, Verim S, Sivrioglu AK, Bozlar U (2013) A rare cause of secondary hypertension: median arcuate ligament compression of the renal artery diagnosed by $\mathrm{CT}$ angiography. BMJ Case Rep, doi: 10.1136/bcr-2013-009937.

18. Singham S, Murugasu P, Macintosh J, Murugasu P, Deshpande A (2010) Left main renal artery entrapment by diaphragmatic crura: spiral CT angiography. Biomed Imaging Interv J, 6: e11. doi: 10.2349/biij.6.2.e11.

19. Thony F, Baguet JP, Rodiere M, Sessa C, Janbon B, Ferretti G (2005) Renal artery entrapment by the diaphragmatic crus. Eur Radiol, 15: 1841-1849. doi: 10.1007/s00330005-2710-4.

20. Visrutaratna P, Srisuwan T, Sirivanichai C (2009) Pediatric renovascular hypertension in Thailand: $\mathrm{CT}$ angiographic findings. Pediatr Radiol, 39: 1321-1326. doi: 10.1007/ s00247-009-1380-9. 